\title{
A COMPARATIVE STUDY OF ULTRASOUND (USG), FINE NEEDLE ASPIRATION CYTOLOGY (FNAC) AND HISTOPATHOLOGICAL EXAMINATION (HPE) OF THYROID SWELLINGS
}

\author{
Mahesh Santhraya G1, Rukma Bhandary², Reena Valsamma George3, Deepalakshmi Tanthry4, Devan P. P5, Vishwas K. Pai ${ }^{6}$, \\ Sowmya Poojary ${ }^{7}$
}

\begin{abstract}
${ }^{1}$ Associate Professor, Department of ENT, AJ Institute of Medical Sciences, Mangalore ${ }^{2}$ Assistant Professor, Department of ENT, AJ Institute of Medical Sciences, Mangalore. ${ }^{3}$ Post Graduate, Department of ENT, AJ Institute of Medical Sciences, Mangalore. ${ }^{4}$ Assistant Professor, Department of ENT, AJ Institute of Medical Sciences, Mangalore. 5 Professor \& HOD, Department of ENT, AJ Institute of Medical Sciences, Mangalore. ${ }^{6}$ Senior Resident, Department of ENT, AJ Institute of Medical Sciences, Mangalore. ${ }^{7}$ Senior Resident, Department of ENT, AJ Institute of Medical Sciences, Mangalore.
\end{abstract}

\begin{abstract}
AIM: To compare the diagnostic accuracy of preoperative Fine Needle Aspiration Cytology (FNAC) and ultrasound (USG) of thyroid swellings with post-operative Histopathological Examination (HPE) results.

METHODOLOGY: A retrospective study of 60 consecutive patients was conducted from January 2013 to February 2014 in ENT department of our hospital. Ultrasound and Aspiration of thyroid swellings were taken after detailed clinical history, physical examination and thyroid function test. Ultrasound and FNAC reports were compared. 20 patients who underwent surgery, these patients FNAC were compared with final histopathological diagnosis.

RESULTS: The sensitivity, specificity, PPV and accuracy of the FNAC when compared with HPE were 75\%, 100\%, 93\% and 100\% which was compared with other studies.

CONCLUSION: Fine Needle Aspiration Cytology (FNAC) is considered gold standard cost effective diagnostic test for diagnosis of thyroid swellings than ultrasound. Based on the cytologic findings patients can be treated accordingly thus avoiding unnecessary surgery.
\end{abstract}

KEYWORDS: Thyroid Swellings, Ultrasound, FNAC, Histopathology.

HOW TO CITE THIS ARTICLE: Mahesh Santhraya G, Rukma Bhandary, Reena Valsamma George, Deepalakshmi Tanthry, Devan P. P, Vishwas K. Pai, Sowmya Poojary. "A Comparative Study of Ultrasound (USG), fine Needle Aspiration Cytology (FNAC) and Histopathological Examination (HPE) of Thyroid Swellings". Journal of Evolution of Medical and Dental Sciences 2015; Vol. 4, Issue 90, November 09; Page: 15543-15545, DOI: 10.14260/jemds/2015/2227.

INTRODUCTION: Diseases of the thyroid gland is a common clinical presentation in general population where the incidence being higher in endemic areas. ${ }^{1}$ The disorders of thyroid gland can be due to inflammatory and neoplastic causes. $^{2}$ A multitude of non-invasive and invasive diagnostic tests like ultrasound, thyroid nuclear scan and Fine Needle Aspiration Cytology (FNAC) is available to the clinician for the evaluation of thyroid swellings. Hence there arises the need for a final diagnostic test that is histopathological examination (HPE).

The head and neck region encompasses a wide range of lesions of thyroid, lymph node and salivary gland with a variety of differential diagnosis ranging from inflammatory to malignancy. This study is undertaken with the objective of comparing the findings of USG, FNAC and HPE of thyroid swellings and to determine the accuracy of each test.

Financial or Other, Competing Interest: None

Submission 14-10-2015, Peer Review 15-10-2015,

Acceptance 27-10-2015, Published 07-11-2015.

Corresponding Author:

Dr. Reena Valsamma George,

Door No. Kadri B, 3-32/10, Sonal House,

Down Town, Kadri Hills Bejai Post,

Mangalore-575004.

E-mail: sweetlittledarwin@hotmail.com

DOI:10.14260/jemds/2015/2227.
MATERIALS AND METHODS: The present study was carried out from January 2013 to February 2014 in ENT department of AJ Institute of medical science, Mangalore, in patients with clinical evidence of thyroid swelling. Ultrasound and Aspiration of thyroid swellings were done after getting informed consent from them and after getting detailed clinical history, physical examination and thyroid function test. Ultrasound and FNAC reports were done in 60 cases out of which 20 patients agreed for surgical intervention and their results were compared with final histopathological diagnosis.

RESULTS: In this study benign lesions found were Multi Nodular Goiter (MNG), Hashimoto's Thyroiditis and Follicular adenoma (FA); Follicular Neoplasm (FN) were considered suspicious and malignant lesions were papillary carcinoma (PC).

DISCUSSION: Ultrasound (USG) of thyroid gland is a simple cost effective noninvasive diagnostic tool for evaluation of thyroid swellings. USG can differentiate solid from cystic lesion and can identify cysts as small as $2 \mathrm{~mm}$. It is performed using a $12 \mathrm{MHz}$ transducer that is optimal for high resolution imaging. Color flow Doppler is useful in assessing vascularity. USG is safe inexpensive procedure with quick result and an excellent patient compliance. 
FNAC is a method first published by Martin and Ellis in $1930 .^{3}$ FNAC was performed by 22-23 gauge needles with $10 \mathrm{ml}$ disposable syringe. $4,5,6$

The specimen was expelled on 2 glass slides according to the material and smeared, wet fixed or air dried followed by Papanicolaus staining. Similarly post thyroidectomy specimens were fixed with $10 \%$ formalin. Sections were taken from different parts of the specimen and processed. The section so obtained were stained with haematoxylin and Eosin (HE) staining.7,8,9 In our study of 20 cases, 1 case of papillary carcinoma diagnosed by FNAC was confirmed by histopathological examination. It is to be stressed that all malignant cases on FNAC need to surgically treated.

CONCLUSION: American Thyroid Association and National Comprehensive Cancer network states that FNAC should be used as the initial diagnostic test because of its superior diagnostic reliability and cost effectiveness before USG. ${ }^{14}$ FNAC has limitations related to specimen adequacy, sampling technique, skill of performing the aspiration, interpretation of the aspirate and overlapping cytological features between benign and malignant follicular neoplasm. ${ }^{15,16}$ Our study is in par with other studies.

The sensitivity, specificity, PPV and accuracy of the test were $75 \%, 100 \%, 93 \%$ and $100 \%$. FNAC is considered gold standard cost effective diagnostic test for diagnosis of thyroid swellings than ultrasound. ${ }^{14}$ Based on the cytologic findings patients can be treated accordingly thus avoiding unnecessary surgery. So this simple test is easily applicable for early diagnosis and for better future management.

\section{REFERENCES:}

1. M. Bouvet, J. I. Feldman, G. N. Gill, et al., "Surgical management of the thyroid nodule:patient selection based onthe results of fine-needle aspiration cytology," Laryngoscope,1992; 102(12): 1353-1356.

2. KC S, Karki R, Rayamajhi P, Rai K, Piya E. Role of FNAC in the diagnosis of thyroid malignancy and its comparison with histopathology. Nep J of ENT head and neck surgery. 2012;3(1): 9-10.

3. Martin H, Ellis EB. Biopsy of needle puncture and aspiration. Ann Surg 1930;92:169-81.

4. Jasani JH, Vaishnani HV, Vekaria PN, Patel D, Shah Y. Retrospective study of fine needle aspiration cytology of head and neck lesions in tertiary care hospital. IJBAR. 2013;4:253-6.
5. Parikh UR, Goswami HM, Shah AM, Mehta NP, Gonsai RN Fine needle aspiration cytology (FNAC) study of thyroid lesions-study of 240 cases. GMJ. 2012;67(2): 25-8.

6. Tilak V, Dhaded AV, Jain R. Fine needle aspiration cytology of head and neck masses. Indian J Pathol Microbiol. 2002;45(1): 23-9.

7. Chauhan S, Darad D, Dholakia A. Fine needle aspiration cytology of needle lesion-an experience at Tertiary care Hospital in Central Gujarat. NJMR. 2012;2: 255-9.

8. Tandon S, Shahab R, Benton JI,Ghush SK, Sheard J, Jones TM. Fine needle aspiration cytology in a regional head and neck cancer center : comparison with systemic review and metaanalysis. Head Neck 2008;30(9):1246-52.

9. Mobley DL, Wakely PE, Frable MAS. Fine needle aspiration biopsy: application to pediatric Head and Neck masses. Laryngoscope 1991;101: 469-72.

10. Dipanwita Das, Sarma MC, Adity Sharma, Datta TK, Lahiri SK,-A Comparative study between fine needle aspiration cytology and histopathological examination in the diagnosis of neoplastic and nonneoplastic lesions of the thyroid gland.Indian J. Prev.Soc.Med.vol.43 no.1,2012.

11. Kessler, H. Gavriel, S. Zahav, et al., "Accuracy andconsistency of fine-needle aspiration biopsy in the diagnosisand management of solitary thyroid nodules." Israel Medical Association Journal, 2005; 7(6): 371-373.

12. Afroze N, Kayani N, Haasan S H. Role of Fine Needle Aspiration Cytology in the Diagnosis of Palpable Thyroid Lesions . Indian L Pathol Microbiol, 2002; 45(3) :241-246.

13. S Gulia, M Chaudhury, E Sitaramam, K Reddy Diagnostic Accuracy of Fine NeedleAspiration Cytology In The Diagnosis Of Thyroid Lesions. Diagnostic Accuracy Of Fine Needle Aspiration Cytology In The Diagnosis Of Thyroid Lesions. The International Journal of Pathology, 2011; 13(1).

14. Arup Senguptha, Ranabir Pal, Sumit Kar, Forhad Akhtar,Subrata Sengupta and Shrayan Pal:FNAC as a primary diagnostic tool in thyroid enlargement/:J Nat Sci Biol Med 2011:Jan-Jun 2(1)113-118.

15. Manoj Gupta, Savitha Gupta, Ved Bhushan Gupta.:Correlation of Fine needle Aspiration Cytology with Histopathology in the diagnosis of solitary thyroid nodule.Journal of Thyroid Research Vol 2010(2010), Article ID 379051.

16. Md.Alamgir Hossain Sikder, AZM Mahfuzur Rahman,MD Abul Khair:Accuracy of FNAC in the diagnosis of thyroid swellings:J.Dhaka National Med Coll.Hos 2012:18(02):4751.

\begin{tabular}{|c|c|c|}
\hline AGE GROUP & NUMBER OF PATIENTS & PERCENTAGE \\
\hline 10-20Yrs & 5 & 8.3 \\
\hline $21-30 Y r s$ & 19 & 31.7 \\
\hline $31-40 Y r s$ & 25 & 41.7 \\
\hline $41-50 Y r s$ & 9 & 15 \\
\hline 51-60Yrs & 2 & 3.3 \\
\hline TOTAL & $\mathbf{6 0}$ & $\mathbf{1 0 0} \%$ \\
\hline \multicolumn{2}{|c|}{ Table 1: Age Distribution } \\
\hline
\end{tabular}




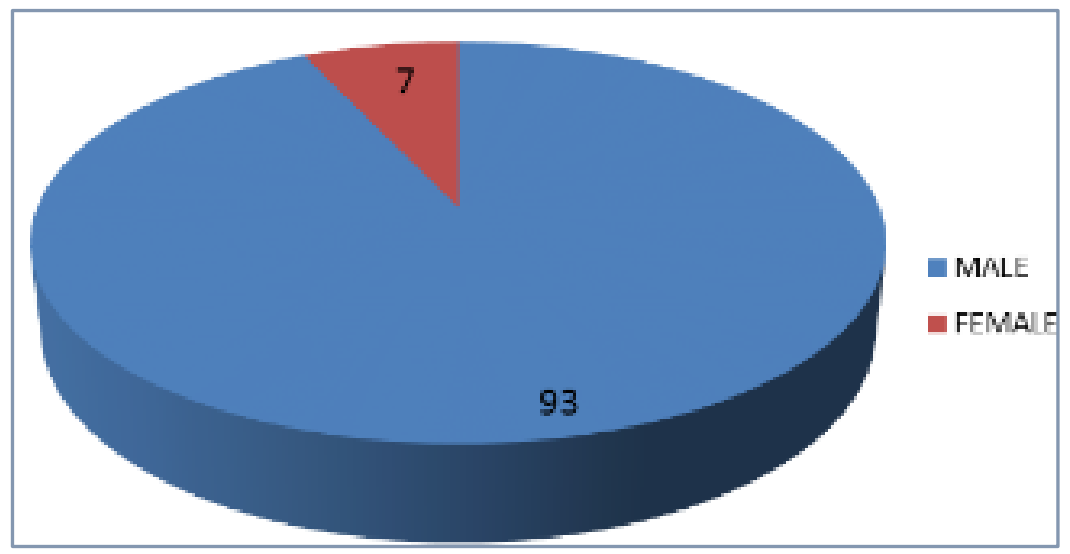

Figure. 1: Represents the sex distribution in the study

In our study FNAC findings revealed that Multinodular Goiter (75\%), Hashimoto's Thyroiditis (5\%), Follicular Adenomas (16.7\%) and Papillary Carcinoma (1.7\%). 3.3\% showed inadequate sample. Figure 2 depicting the comparison of FNAC and HPE in our study.

\begin{tabular}{|c|c|c|}
\hline & FNAC & HPE \\
\hline MultinodularGoitre & 45 & 14 \\
\hline Hashimoto's Thyroiditis & 3 & 3 \\
\hline Follicular Adenoma & 10 & 2 \\
\hline Papillary Carcinoma & 1 & 1 \\
\hline \multicolumn{2}{|c|}{ Table 2: Correlation of FNAC and HPE of Thyroid Swellings } \\
\hline \multicolumn{2}{|c}{} \\
\hline
\end{tabular}

\begin{tabular}{|c|c|c|}
\hline & USG (\%) & FNAC (\%) \\
\hline BENIGN & $58(96.7 \%)$ & $58(96.7 \%)$ \\
\hline MALIGNANT & 0 & $1(1.7 \%)$ \\
\hline INDETERMINANT & $2(3.3 \%)$ & $1(1.7 \%)$ \\
\hline TOTAL & $\mathbf{6 0 ( 1 0 0 \% )}$ & $\mathbf{6 0}(100 \%)$ \\
\hline \multicolumn{3}{|c|}{ Table 3: Relationship of USG and FNAC Findings } \\
\hline
\end{tabular}

Ultrasound findings revealed 58 were benign and 2 were showing features suspicious of malignancy to which FNAC correlation was advised.

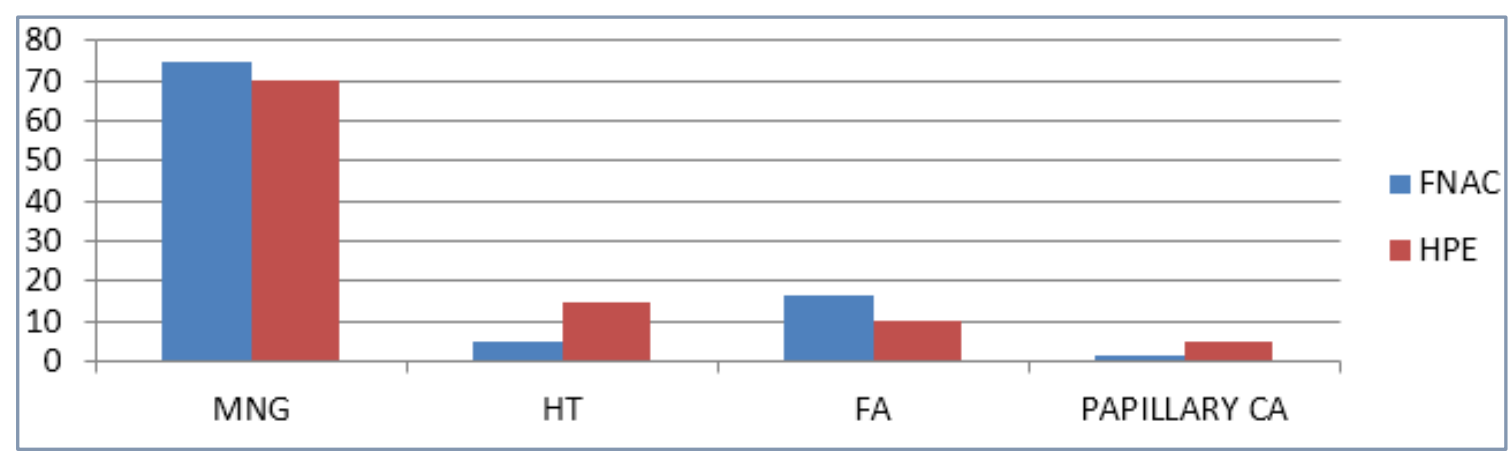

Figure 2: Relationship of FNAC and HPE Findings

\begin{tabular}{|c|c|c|c|c|c|c|}
\hline STUDY/YEAR & $\begin{array}{c}\text { NO. OF } \\
\text { PATIENTS }\end{array}$ & SENSITIVITY & SPECIFICIY & ACCURACY & $\begin{array}{c}\text { NEGATIVE } \\
\text { PREDICTIVE } \\
\text { VALUE }\end{array}$ & $\begin{array}{l}\text { POSITIVE } \\
\text { PREDICTIVE } \\
\text { VALUE }\end{array}$ \\
\hline $\begin{array}{c}\text { Alfrose } \\
\text { et } \mathrm{al} / 2002\end{array}$ & 170 & $61.9 \%$ & $99.3 \%$ & $94.5 \%$ & $94.7 \%$ & $92.8 \%$ \\
\hline $\begin{array}{c}\text { Kessler } \\
\text { et } \mathrm{al} / 2005\end{array}$ & 170 & & $98.5 \%$ & $87 \%$ & $76.6 \%$ & $98.7 \%$ \\
\hline $\begin{array}{l}\text { Manoj gupta } \\
\text { et al/2006 }\end{array}$ & 75 & $80 \%$ & $86.6 \%$ & $84 \%$ & $86.6 \%$ & $80 \%$ \\
\hline S S Guli/2010 & 140 & $100 \%$ & $90 \%$ & $92.3 \%$ & $90.5 \%$ & $100 \%$ \\
\hline 0ur study/2014 & 2014 & $75 \%$ & $100 \%$ & $100 \%$ & & $93 \%$ \\
\hline \multicolumn{7}{|c|}{ Table 4: Comparison of our Study of FNAC with other Studies. ${ }^{10,11,12,13}$} \\
\hline
\end{tabular}

